\title{
Ferritin, finger clubbing, and lung disease
}

\author{
JM SHNEERSON, BM JONES \\ From the Department of Medicine, Westminster Hospital, London and the Department of Haematology, \\ Welsh National School of Medicine, Cardiff
}

ABSTRACT The serum ferritin concentration has been determined by an immunoradiometric assay in 90 subjects with a variety of pulmonary diseases. No association between ferritin concentrations and finger clubbing has been found in any of the diseases studied. Ferritin levels were significantly raised in the subjects with bronchial carcinoma, but were not useful in monitoring recurrence of the tumour. Pulmonary artery and pulmonary vein ferritin concentrations were similar to systemic venous concentrations. It is therefore unlikely that the tumour releases ferritin into the pulmonary circulation. Ferritin levels were raised in patients with acute pneumonias but did not correlate with the total white cell count or erythrocyte sedimentation rate. Serum ferritin concentrations were also increased in a variety of chronic lung diseases but were normal in subjects with asbestosis.

Finger clubbing is a common and well-recognised physical sign but its pathogenesis is obscure. Histological examination of clubbed fingers has revealed an increase in vascular connective tissue. ${ }^{1}$ Blood flow to clubbed fingers is increased ${ }^{2}$ and most of the blood probably passes through arteriovenous anastomoses. ${ }^{3}$

The frequent association of clubbing with right to left shunts has led to the hypothesis that a circulating factor normally removed by the lungs acts on the finger tips to increase their blood flow. The chemical nature of the circulating vasodilator has never been demonstrated. $\mathrm{Hall}^{4}$ pointed out that ferritin, which is normally inactivated in the lungs, inhibits the vasoconstrictor effect of catecholamines. Ferritin was originally called vaso-depressor material (VDM) because of this action. ${ }^{5}$ It also has an antidiuretic effect. ${ }^{6}$ Hall $^{4}$ and Hall and Laidlaw ${ }^{7}$ showed that reduced ferritin was present in mixed venous blood but only in arterial blood if clubbing was present. The increased blood flow to clubbed fingers was abolished by rutin, a specific ferritin antagonist. They postulated that reduced ferritin caused vasodilatation in the finger tips and, consequently, finger clubbing.

This theory could not be confirmed until recently because the original bioassay of ferritin was insensitive. Recently a radioimmunoassay 8 has been developed, and this has been used in this study in an attempt to correlate the presence of clubbing with

Address for reprint requests: Dr JM Shneerson, Newmarket General Hospital, Newmarket, Suffolk. the serum ferritin concentration. The concentration of ferritin in a variety of lung conditions has also been examined and its usefulness as a tumour marker in bronchial carcinoma ${ }^{9}$ has been assessed.

\section{Methods}

The details of the 90 subjects studied are shown in table 1. Those with bronchial carcinoma were subdivided histologically into epidermoid, small cell, and adenocarcinoma subgroups and also according to the presence or absence of extrapulmonary metastases. The diagnosis of asbestosis had been madc in each case by the pneumoconiosis medical panel from five to 11 years previously and the progression of the disease over this period was assessed radiologically. The chronic lung disease group comprised eight patients with untreated pulmonary tuberculosis (four with clubbing), six with cryptogenic fibrosing alveolitis (four with clubbing), nine with

Table 1 Details of subjects

\begin{tabular}{lrlrrrr}
\hline Group & Number & Age & \multicolumn{2}{c}{ Sex } & \multicolumn{2}{c}{ Clubbing } \\
& & $($ mean $\pm S D)$ & $M: F$ & Present & Absent \\
\hline All & 90 & $60 \cdot 3 \pm 11 \cdot 8$ & $68: 22$ & 41 & 49 \\
Bronchial carcinoma & 24 & $64 \cdot 3 \pm 9 \cdot 1$ & $15: 9$ & 12 & 12 \\
Asbestosis & 28 & $62 \cdot 9 \pm 7 \cdot 8$ & $28: 0$ & 14 & 14 \\
Chronic lung disease & 26 & $56 \cdot 2 \pm 12 \cdot 8$ & $16: 10$ & 13 & 13 \\
Hereditary clubbing & 2 & $54 \cdot 5 \pm 0.5$ & $2: 0$ & 2 & 0 \\
Acute pneumonia & 10 & $56 \cdot 1 \pm 19 \cdot 6$ & $7: 3$ & 0 & 10 \\
\hline
\end{tabular}


bronchiectasis (four with clubbing), and three with a lung abscess (one with clubbing). Two subjects with hereditary clubbing and 10 with acute bacterial or mycoplasma pneumonia were also studied. The presence or absence of finger clubbing was assessed independently by two physicians and only subjects in whom agreement was reached were included in the study.

Serum ferritin concentrations were determined by an immunoradiometric assay ${ }^{8}$ with antibodies to human spleen ferritin, and human spleen ferritin as standard. In patients with bronchial carcinoma, ferritin concentrations were also determined with a radioimmunoassay for acidic (HeLa cell) ferritin. ${ }^{10}$ The distribution of ferritin concentrations in healthy adults is skewed, but the level is less than $300 \mathrm{ng} / \mathrm{ml}$ in $95 \%$ of normal subjects. Ferritin levels were measured in each patient at presentation. Repeat estimations were made in five subjects from one week to 14 months after resection of a bronchial carcinoma. In three patients with bronchial carcinoma ferritin estimations on pulmonary artery and pulmonary venous blood draining the tumour were made at thoracotomy. The normal and malignant lung tissue was also analysed for the basic (spleen type) and acidic (HeLa cell type) ferritin in two of these subjects.

A full blood count was carried out in all the patients, erythrocyte sedimentation rate (ESR) (Westergen method) in 72 , and aspartate transaminase, alanine transaminase, and alkaline phosphatase in all except the asbestosis patients. None of the patients had the haematological features of iron deficiency and none had raised liver enzymes.

The significance of the ferritin concentrations was assessed by the two-tailed Kolmogorov-Smirnov test. Their relationship to the white blood count (WBC) and ESR was tested by using the Spearman rank correlation coefficients.

\section{Results}

\section{RELATIONSHIP TO FINGER CLUBBING}

The observed ferritin concentrations were not related to the presence of finger clubbing in the whole group of patients (excluding those with acute pneumonia) or in those with bronchial carcinoma or chronic lung disease analysed separately. No relationship to finger clubbing emerged when the carcinoma group was subdivided histologically or according to the presence of metastases. Ferritin and finger clubbing were not related in the asbestosis group as a whole or in those with progressive or static disease analysed separately. The single patient with hypertrophic osteoarthropathy caused by a bronchial carcinoma had a ferritin level of $518 \mathrm{ng} / \mathrm{ml}$. One patient, with a lung abscess, was tested before and after finger clubbing appeared but her ferritin concentrations were normal (140 and $227 \mathrm{ng} / \mathrm{ml}$ ) on both occasions. The ferritin concentration was $679 \mathrm{ng} / \mathrm{ml}$ in a patient with tuberculosis when his clubbing was mild and $894 \mathrm{ng} / \mathrm{ml}$ when it had progressed significantly. The ferritin concentration was normal in both patients with hereditary clubbing.

\section{BRONCHIAL CARCINOMA}

The serum ferritin concentrations were significantly higher in the bronchial carcinoma group than in normal subjects ${ }^{11}(p<0.002)$. There was no significant difference between the histological subgroups but those with metastases had a higher ferritin concentration than those without $(p<0.05)$. In view of the high levels seen in these patients, serial measurements were made in five patients after resection of the primary tumour to see if changes in the concentration indicated recurrence of disease (figure). No trend was apparent.

To test whether the high ferritin concentrations were caused by ferritin released by the primary tumour, the systemic venous concentrations were compared with those in the pulmonary artery and vein in three patients (table 2). The pulmonary vein values were not significantly different from the pulmonary artery values. HeLa cell type ferritin was not detected in blood from the pulmonary artery, pulmonary vein, or systemic blood in these subjects (table 2).

\section{ASBESTOSIS}

The ferritin concentrations in the subjects with asbestosis were similar to those in the normal population. ${ }^{11}$ There was no association with progression of the asbestosis.

\section{CHRONIC LUNG DISEASE}

The ferritin concentration was significantly higher $(p<0.05)$ in patients in this group than in normal people. ${ }^{11}$ There was no significant difference between the aetiological subgroups.

\section{ACUTE PNEUMONIA}

The ferritin concentration was significantly increased $(\mathrm{p}<0.0001)$ during acute pneumonia relative to the normal population. ${ }^{11}$ It was not correlated with the total white blood cell count or ESR.

\section{Discussion}

The possibility that ferritin is the vasodilator responsible for finger clubbing was raised by the findings of Hall ${ }^{4}$ and Hall and Laidlaw. ${ }^{7}$ More recently the presence of clubbing in thalassaemia has been 


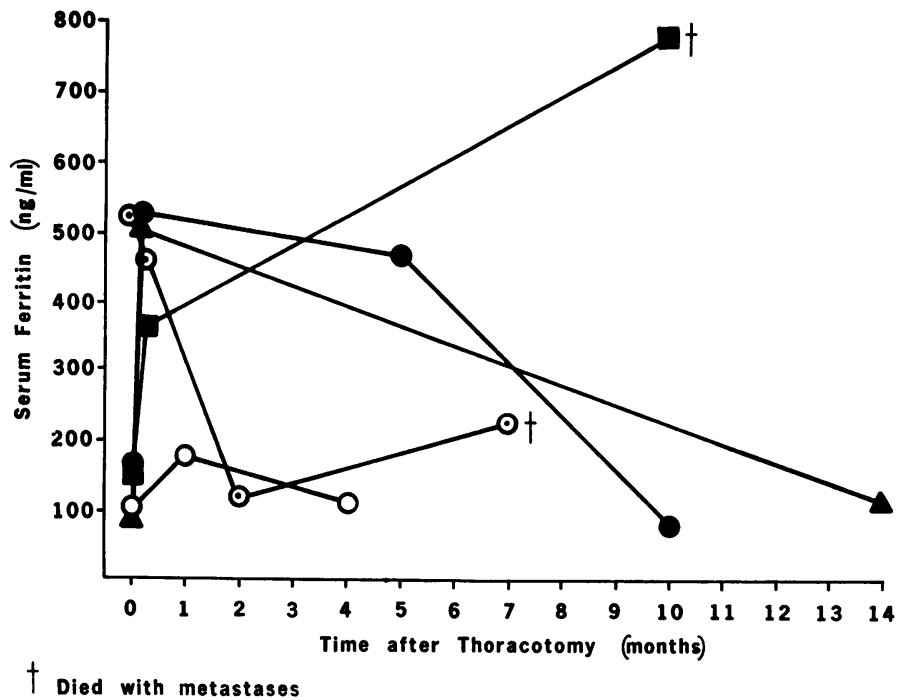

Figure Serial ferritin estimations in five subjects before and after resection of bronchial carcinoma.

Table 2 Serum ferritin measurements during thoracotomy

\begin{tabular}{llll}
\hline Patients & \multicolumn{2}{l}{$\begin{array}{l}\text { Spleen type ferritin concentration } \\
\text { (HeLa type ferritin concentration }\end{array}$} \\
\cline { 2 - 4 } & $\begin{array}{l}\text { Pulmonary } / \mathrm{ml} \text { ) } \\
\text { artery }\end{array}$ & $\begin{array}{l}\text { Pulmonary } \\
\text { vein }\end{array}$ & $\begin{array}{l}\text { Systemic } \\
\text { vein }\end{array}$ \\
\hline 1 & 92 & 118 & 108 \\
2 & $(<2)$ & $(<2)$ & $(<2)$ \\
3 & 551 & 490 & 518 \\
$(<2)$ & $(<2)$ & $(<2)$ \\
& 84 & 82 & 93 \\
$(<2)$ & $(<2)$ & $(<2)$ \\
\hline
\end{tabular}

correlated with the severity of iron overloading. ${ }^{12}$ Ferritin is an iron-storage protein and, although it was not measured, its serum concentration would almost certainly be raised in these patients. In addition, koilonychia, which in some respects is the opposite of clubbing, is a feature of severe iron deficiency.

Extrapulmonary conditions that affect serum ferritin concentration were excluded in this study by the history, examination, full blood count, and measurement of hepatic enzymes. Iron deficiency decreases ferritin levels ${ }^{13}$ and iron overload, ${ }^{13} 14$ and liver disease ${ }^{14}$ are known to increase them. None of these subjects appeared to be iron deficient or overloaded and none had elevated liver enzymes.

The ferritin concentrations in the 41 subjects with finger clubbing were not significantly different from the 39 subjects (excluding those with acute pneumonia) without clubbing. There was no relationship to clubbing when the bronchial carcinoma, asbestosis, or chronic lung disease groups were analysed separately. The ferritin level was not related to clubbing in any of the histological subgroups of the bronchial carcinoma or in either those with or without metastases. Both patients with hereditary clubbing had normal ferritin levels.

The ferritin concentration is therefore not related to the presence or absence of finger clubbing. Nevertheless, it is possible that high levels in the early stages of clubbing could be a necessary factor in its development and that once clubbing is established the ferritin level is immaterial. One patient with a lung abscess, however, was studied before and after clubbing appeared but her ferritin levels were normal on both occasions. One other subject with tuberculosis was studied when his clubbing was progressing and later when it was fully developed. His ferritin levels were similar on the two occasions. Thus ferritin does not appear to play any role in the early stages of clubbing and a search for other vasoactive agents is needed.

Biochemical markers of tumour mass have proved useful in many types of neoplasm although not for bronchial carcinoma. Ferritin has been suggested as a tumour index substance. It has been detected in breast carcinoma tissue ${ }^{15}$ and its serum level correlates with recurrence of the tumour after initial surgery. ${ }^{16} 17$ Alpha-two $\mathrm{H}$ globulin is almost identical to ferritin 1819 and has also been used as a tumour index substance. ${ }^{20}$ Aungst, using a bioassay, detected ferritin in seven out of nine subjects with bronchial carcinoma and two subsequent studies have demonstrated it in $61 \%$ and $72 \%$ of such patients. ${ }^{21-23}$ Ferritin has been found in extracts of bronchial carcinoma, but not in normal lung. ${ }^{23}$ 
In the present study, the ferritin concentration was significantly raised in the subjects with bronchial carcinoma, but was not related to the histological type. The ferritin concentration in venous, pulmonary arterial, and pulmonary venous blood measured during resection of the tumour were all similar suggesting that it was not being liberated into the pulmonary circulation in clinically significant amounts by the tumour. The high serum ferritin values seen in bronchial carcinoma may be caused by the "reticulo-endothelial block" to iron uptake seen in other tumours, ${ }^{19}$ and which results in increased iron stores.

Samples of bronchial carcinoma removed from two patients showed increased quantities of acidic (HeLa cell type) ferritin compared to normal lung tissue but even so the predominant ferritin was still the more basic type found in liver and spleen. The acidic ferritin content, expressed as a percentage of the total ferritin, was 0.89 for normal lung and 4.6 and $7 \cdot 1$ for the tumours. Although increased levels of acidic ferritin were detected in the tissues there was no corresponding increase of acidic ferritin in the serum of these two patients. No acidic ferritin was detectable in samples from the pulmonary artery and vein or in systemic venous blood of $80 \%$ of the patients with carcinoma of the lung who were tested. The highest level in the remaining $20 \%$ was only $3 \mathrm{ng} / \mathrm{ml}$ so it is unlikely that this acidic ferritin is being released from the carcinoma into the circulation in quantities which could be clinically significant.

The usefulness of spleen type ferritin as a predictor of relapse in bronchial carcinoma after attempted curative resection of the primary tumour was observed in five patients. The high values seen one week after operation were probably the result of the trauma of the operation. The subsequent values did not correlate well with the clinical course of the disease. Nevertheless, among the whole group of bronchial carcinoma subjects those with metastases did have a significantly higher $(p<0.05)$ ferritin concentration that those without. This has been previously noted ${ }^{23}$ but, in the individual subject, serial estimation of ferritin concentrations do not appear to be useful in monitoring progress. Further studies with larger numbers of subjects are required.

The influence of acute lung disease on ferritin concentration was studied. The ferritin concentration was significantly higher than normal $(p<0.0001)$. Ferritin is known to be an "acute phase protein" and its level is raised in inflammatory conditions. ${ }^{24}$ In this study the ferritin level was not related to the total white cell count (WBC) or the ESR, which were used as indices of the severity of the inflammation. In addition, the ferritin values were not related to the WBC in the patients with bronchial carcinoma, asbestosis, or chronic lung diseases or to the ESR except in the asbestosis group. From these results the high ferritin levels seen during acute pneumonias may be caused by metabolic changes in the lung rather than by the systemic inflammatory reaction. The explanation of the finding of raised ferritin concentrations in the chronic lung disease group but of normal values in the asbestosis group is obscure.

We thank Dr PA Emerson for permission to study patients under his care, Dr I Coutts for his assistance with the asbestosis subjects, and Miss Barbara Copland for her secretarial help.

\section{References}

${ }^{1}$ Lovell RRH. Observations on the structure of clubbed fingers. Clin Sci 1950;9:299-321.

2 Wilson GM. Local circulatory changes associated with clubbing of the fingers and toes. $Q J$ Med 1952;21:201-14.

${ }^{3}$ Racoceanu SN, Mendlowitz M, Suck AF, Wolf RL, Naftchi NE. Digital capillary blood flow in clubbing. ${ }^{85} \mathrm{Kr}$ studies in hereditary and acquired cases. $A n n$ Intern Med 1971 ; 75 :933-5.

${ }^{4}$ Hall GH. The cause of digital clubbing. Testing a new hypothesis. Lancet 1959;1:750-3.

${ }^{5}$ Mazur A, Shorr E. Hepatorenal factors in circulatory homeostasis. ix: the identification of the hepatic vasodepressor substance, VDM, with ferritin. $J$ Biol Chem 1948;176:771-87.

- Baez S, Mazur A, Shorr E. Hepatorenal factors in circulatory homeostasis. xx: antidiuretic action of hepatic vasodepressor, VDM (ferritin). Am J Physiol 1950;162: 198-212.

${ }^{7}$ Hall GH, Laidlaw DA. Further experimental evidence implicating reduced ferritin as a cause of digital clubbing. Clin Sci 1963;24:121-6.

${ }^{8}$ Dawkins S, Cavill I, Ricketts C, Worwood M. Variability of serum ferritin concentration in normal subjects. Clin Lab Haematol 1979;1:41-6.

9 Coombes RC, Ellison ML, Neville AM. Biochemical markers in bronchogenic carcinoma. $\mathrm{Br} J$ Dis Chest 1978;72:263-87.

10 Jones BM, Worwood M, Jacobs A. Serum ferritin in patients with cancer: Determination with antibodies to HeLa cell and spleen ferritin. Clin Chim Acta 1980;106;203-14.

${ }^{11}$ Jacobs A, Worwood M. Ferritin in serum. Clinical and biochemical implications. N Engl J Med 1975;292:951-6.

${ }^{12}$ Sinniah D, White JC, Omar A, Murugasu R, Iyngkaran N. Digital clubbing-a clinical sign in thalassemia. $J$ Pediatr 1978;92:597-9.

13 Jacobs A, Miller F, Worwood M, Beamish MR, Wardrop CA. Ferritin in the serum of normal subjects and patients with iron deficiency and iron overload. $\mathrm{Br}$ Med $J 1972 ; 4: 206-8$.

14 Prieto J, Barry M, Sherlock S. Serum ferritin in patients with iron overload and with acute and chronic liver diseases. Gastroenterology 1975;68:525-33.

${ }^{15}$ Marcus DM, Zinberg N. Isolation of ferritin from human and mammary and pancreatic carcinomas by means of antibody immunoadsorbents. Arch Biochem Biophys $1974 ; 162: 493-501$.

16 Marcus DM, Zinberg N. Measurement of serum ferritin by radio-immunoassay, results in normal individuals 
and patients with breast cancer. $J$ Natl Cancer Inst 1975; 55:791-5.

17 Jacobs A, Jones B, Ricketts C, Bulbrook RD, Wang DY. Serum ferritin concentration in early breast cancer. Br J Cancer 1976;34:286-90.

${ }^{18}$ Buffe D, Rimbaut C. $a_{2}-\mathrm{H}$-globulin, a hepatic glycoferroprotein: characterization and clinical significance. $A n n$ NY Acad Sci 1975;259:417-26.

19 Worwood M. Serum ferritin. CRC Crit Rev Clin Lab Sci 1979;10:171-204.

${ }^{20}$ Buffe D, Rimbaut C, Burtin P. Serumanalysen am kindlichen Hepatom und Teratompatienten zur Bestimmung des Alpha-1-Foeto-proteins und Alpha-2-H-
Globulins, sowie deren diagnostische und prognostische Bedeutung. Pädiatre Pädol 1973;8:40-44.

${ }^{21}$ Aungst CW. Ferritin in body fluids. J Lab Clin Med 1968; $71: 517-22$.

${ }^{22}$ Niitsu Y, Urushizaki I. Measurement of serum ferritin and its clinical application. Acta Haematol Jpn 1978;41: 1301-8.

${ }^{23}$ Gropp C, Havemann K, Lehmann F-G. Carcinoembryonic antigen and ferritin in patients with lung cancer before and during therapy. Cancer 1978;42:2802-8.

${ }^{24}$ Lipschitz DA, Cook JD, Finch CA. A clinical evaluation of serum ferritin as an index of iron stores. $N$ Engl $J$ Med 1974;290:1213-6. 